Hydraulic Engineering Repository

Ein Service der Bundesanstalt für Wasserbau

Eslami, S.; Van Rijn, Leo C.; Walstra, D. J.; Luijendijk, A. J.; Stive, M. J. F. A Numerical Study on Design of Coastal Groins

Verfügbar unter / Available at:

https://hdl.handle.net/20.500.11970/100268

Vorgeschlagene Zitierweise / Suggested citation:

Eslami, S.; Van Rijn, Leo C.; Walstra, D. J.; Luijendijk, A. J.; Stive, M. J. F. (2010): A Numerical Study on Design of Coastal Groins. In: Burns, Susan E.; Bhatia, Shobha K.; Avila, Catherine M. C.; Hunt, Beatrice E. (Hg.): Proceedings 5th International Conference on Scour and Erosion (ICSE-5), November 7-10, 2010, San Francisco, USA. Reston, Va.: American Society of Civil Engineers. S. 501-510. 


\title{
A Numerical Study on Design of Coastal Groins
}

\author{
S. Eslami ${ }^{1,2}$, Leo C. vanRijn ${ }^{1}$, D.J. Walstra ${ }^{1,2}$, A.J. Luijendijk ${ }^{1}$, M.J.F. Stive ${ }^{2}$
}

${ }^{1}$ Deltares|Delft Hydraulics, Section Hydraulic Engineering (HYE), P.O.BOX 177, $2600 \mathrm{MH}$ Delft, the Netherlands, TEL: + $31(0) 88335$ 8273, fax : +31 (0)88 335 8582; email: Sepehr.EslamiArab@deltares.nl

${ }^{2}$ Delft University of Technology, Department of hydraulic Engineering, Chair of Coastal Engineering, Stevinweg 1, 2628 CN, Delft, the Netherlands TEL: +31 (0)15 2782811; email: D.J.R.Walstra@tudelft.nl

\begin{abstract}
Numerical models become attractive means of study, when considering the limited knowledge and guidance on functional design of coastal groins. In the present article, a process-based 3D numerical model (Delft3D) is verified against two different datasets. For application on design of straight open (normal) groins, Badiei et. al. 1994 laboratory measurements, and in case of T-Head groins Ozolcer et. al. 2004 field measurements are considered. In case of normal groins, the model showed good agreement with the observations, hence, a design exercise and method has been developed. In case of T-Head groins, the model showed sensitivity to the numerical representation of the structure, while still satisfactory resemblance was perceived. Comparing to the present design rules, application of a numerical study is of crucial importance.
\end{abstract}

\section{INTRODUCTION}

Groins are popular means of coastal protection against erosion and are found along the coast worldwide, although according to CEM (Coastal Engineering Manual 2003), "they are probably the most misused and improperly designed of all coastal structures". Groins, albeit having a simple concept, their interaction with the beach is complex, and existing functional design guidance is limited. The recent developments in numerical modeling, has provided better tools to study the hydrodynamic and morphological phenomena in presence of groins to find more sophisticated design approaches. Usage of straight open groins has shown a variety of failure mechanisms worldwide. Therefore, as an alternative, T-Head groins seem to be showing more promising behavior when coastline protection/generation is of highest priority. Examples of successful T-head groin fields can be found in Argentina (personal contact Leo vanRijn) and Turkey.

A groin simply blocks part of alongshore sand transport and causes it to accumulate in a fillet on the groin's up-drift side. This accumulation reorients the shoreline and reduces the angle between the shoreline and the prevailing incident wave direction. The reorientation reduces the local rate of alongshore sand transport to produce accumulation and/or redistribution of sand up-drift of the groin. Wave diffraction causes reduced wave energy in the lee of the groins relative to the midcompartment, mean water-level setup gradients, and setup induced currents behind the groin. These contribute to complex current circulation patterns that move sediment alongshore and offshore along the lee side of the groin (Dean 1978). The 
strength of these internal current patterns depends on groin plan-form geometry, but also on groin cross-sectional elevation and permeability across the surf zone. For normal wave incidence, the groin system can create strong local currents and rip currents, which add to the offshore movement of beach material during more extreme situations; therefore, the expectation is by construction of T-Head groins, and reducing wave transmission and increasing wave asymmetry, cross-shore sediment transport is interrupted.

Hanson \& Kraus 1989, using GENESIS (a coastline model) introduced four key parameters in functional design of groins:

1. Groin Bypassing; depth at groin tip/breaking wave height (or the ratio between the length of the groin and the width of the surf-zone $\mathrm{Lg} / \mathrm{Lb}$ )

2. Permeability factor; representing groin elevation and groin porosity

3. Ratio of net transport/gross rate

4. Ratio of distance between the groins over the groin length; a value of 2-3 is proposed by SPM (Shore Protection Manual 1984) for the proper functioning of shore normal groins.

However, in such models, a realistic distribution of long-shore current and sediment transport across the surf zone, cross-shore sediment transport, beach profile shapes with bars and troughs and other phenomena are missing. Therefore, with modern process-based two/three-dimensional morphological models, better understanding of groins for purpose of functional design is envisaged.

\section{Description of the Model}

In this study, the process-based model Delft3D is employed for hydrodynamic and morphological simulations. The model includes various modules such as, Delft3D-FLOW for 2 or 3-dimensional simulations of flow and sediment transport and Delft3D-WAVE for wave propagation simulations that runs online with Delft3D-FLOW providing wave forcing for the flow module.

Delft3D-WAVE runs the phase averaged spectrum model SWAN (see Holthuijsen et al. 1993). SWAN, in fact, solves the conservation of action density over the wave grid. Usually, the spectrum wave models determine the evolution of the action density $N(\vec{x}, t ; \sigma, \theta)$ in space, $\vec{x}$, and in time $t$. Where, $\sigma$ is the frequency (as observed with a frame of reference moving with current velocities) and $\theta$ is the wave direction normal to the wave crest of each spectral component. The action density is a realization of energy density $E(\sigma, \theta)$, while $N=E / \sigma$. The advantage of the action density is based upon its conservation during propagation in the absence of ambient current, whereas energy density is not (Whitman, 1974).

Delft3D-Flow module solves the non-linear unsteady shallow water equations derived from the three dimensional Navier-Stokes equations for incompressible free surface flow, under the Boussinesq assumption, in two (depth averaged) or in three dimensions. This system of equation consists of horizontal equation of motion, continuity equation and conservation of constituent (in our case sediment). In Delft3D-Flow, the 3D turbulent eddies are computed by means of an algebraic $k-\varepsilon$ turbulence model, where, $\mathrm{k}$ is the turbulent kinetic energy, and $\varepsilon$ is the dissipation rate of kinetic energy. To account for sediment transport, this module computes the 
sediment transport and its gradients using Vanrijn 2004 formulation (see also van Rijn 2006). The advantage of this formulation is the decomposition of different sediment transport components. These components are bed load and suspended load, while each of them has a wave related and a current related contribution. The approach provides useful calibration tools (a coefficient for every component) to adapt different physical conditions (for further information see Lesser et al. 2004).

\section{VALIDATION OF THE MODEL IN CASE OF STRAIGHT OPEN GROINS}

Badiei et al. 1994 employed a series of mobile bed process physical models to investigate effects of groins on evolution of shore morphology under attack of waves approaching with an angle towards the shoreline. Their observations have been used to verify the model performance in application of straight open groins with grain size of $\mathrm{D}_{50}=0.2 \mathrm{~mm}$. The tests start with a straight beach and a constant slope of $1: 10$ exposed to waves with $\mathrm{H}_{\mathrm{s}}=8 \mathrm{~cm}, \mathrm{~T}_{\mathrm{p}}=1.15 \mathrm{sec}$ and an angle of 11.6 degrees relative to normal to the coast for 4 hours to get some bar and trough in cross-shore direction (NT1 test). After 4 hours, the basin is surveyed to measure the beach response and the groins with different lengths are placed afterwards (called NT4 test when $\mathrm{Lg} / \mathrm{Lb}=1.4$ and NT5 when $\mathrm{Lg} / \mathrm{Lb}=0.8$ ). The experiments continue for another 8 hours in presence of groins. A similar approach is considered in the numerical verification of this study.

The primary tests showed that the model was not capable of simulating in the laboratory scale and a scale-up to prototype was needed. The scaling up formulation of van Rijn 2009 is used for this purpose and everything is scaled up for 25 times. Eventually, a coast with $1: 10$ slope and sediment size of $0.2 \mathrm{~mm}$ is considered, which is exposed to a wave field with $\mathrm{H}_{\mathrm{s}}=2 \mathrm{~m}$ and $\mathrm{T}_{\mathrm{p}}=5.6 \mathrm{sec}$ in prototype with the same approach angle of 11.6 degrees as in laboratory scale.

Initially, the model is verified for no-groin situation (NT1 test). In this phase, a calibration, for the sediment transport coefficients, has been carried out to fit the computed cross-shore profile with the measured profile. Figure 1 shows the measured and simulated profiles.

The figure shows an overestimation of accretion on the coastline and a clear bar and trough, while in the lab a step is more distinguished. This is due to the fact that $8 \mathrm{~cm}$ wave height in the laboratory hardly moves the sediment size of $0.2 \mathrm{~mm}$; therefore, most of the bed changes occur close to the coastline due to higher turbulence, while in prototype the model shows a clear offshore sediment exchange, since a wave height of $2 \mathrm{~m}$ is attacking the coast.

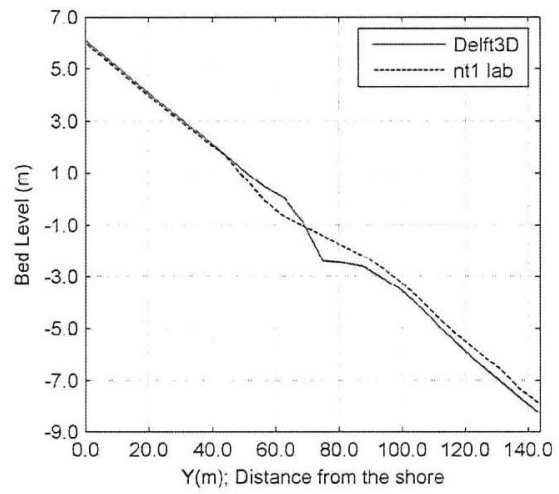

Figure 1, bed level after 4 hours in laboratory and prototype 
In general, there is hardly any beach in the nature with $\mathrm{D}_{50}=0.2 \mathrm{~mm}$ and a $1: 10$ slope; the significant changes happening in the simulation are clearly representing the physics of prototype scale that are not present in the lab scale. Accepting the computed profile, the groins are then placed in the model. The groins are represented as so-called thin-dams that do not let any flow exchange or energy transfer (in wave simulations) between two adjacent grids. No permeability or overflowing is considered in these simulations. The model has been calibrated again for the sediment transport contributions. The net (NT4/NT5-NT1) computed sedimentation and erosion is given in Figure 2 below for NT4 \& NT5 tests.
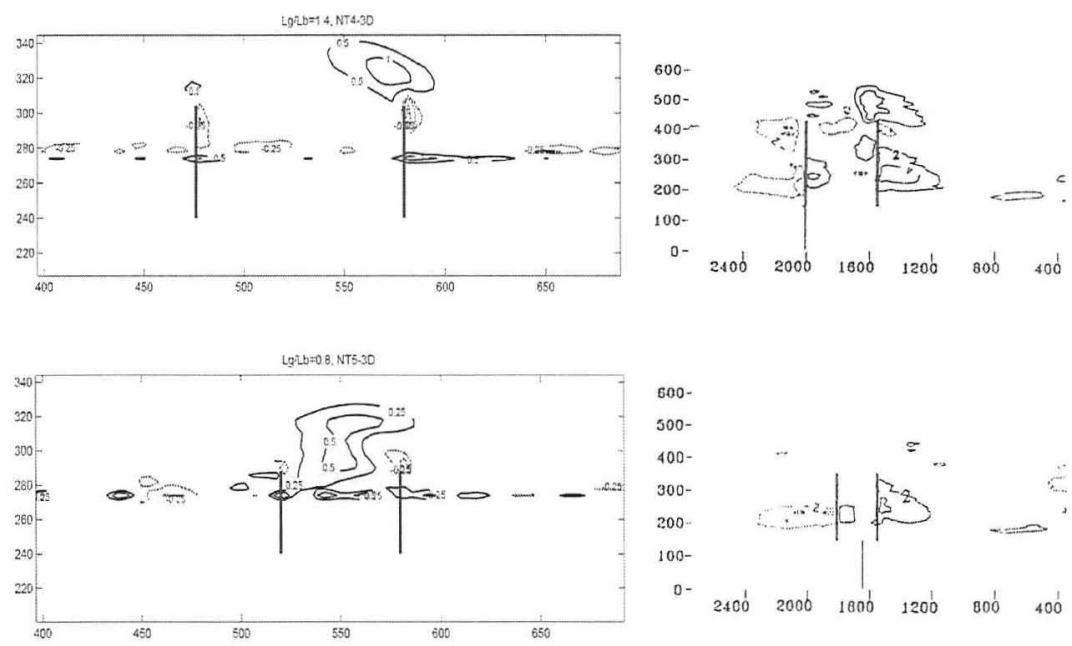

Figure 2 net computed effect of the groins for NT4 (upper left in $m$ ) and NT5 (lower left in cm) vs. laboratory measurements of Badiei et al. 1994 on the right; Note the scale difference in laboratory and prototype $(0.5 \mathrm{~m}$ contour line in prototype is compared with $1 \mathrm{~cm}$ contour line in the lab)

The model shows relatively good performance for longer groins (NT4), but not a satisfactory for shorter groin. This can be explained in the initial profile. The computed initial profile (see Figure 1) has a steeper foreshore, which results in larger undertow velocities, especially along the groin, and eventually stronger bypassing at the tip of the right groin. The resemblance in case of longer groin is due to the fact that the alongshore transport is completely diverted offshore, due to extension of the groins outside the surfzone, and the difference in the initial foreshore slope is not an issue anymore. Note that, similar simulations in two-dimensional domain did not provide any better tool since the cross-shore processes were not properly included. This verification shows that a process-based model can be used to simulate morphological effects of the groins with extra caution on the sediment transport formulation used and calibration of the model with sufficient knowledge of present physics in the problem. 


\section{APPLICATION OF THE MODEL ON DESIGN OF A GROIN FIELD}

Based on the validation in previous section an exercise is introduced to challenge the model and its applicability on design of a groin field. A Dean equilibrium cross-shore profile is considered. The beach is open to $1 \mathrm{~m}$ waves with $T_{\text {peak }}=5 \mathrm{sec}$. the waves are approaching the coast with an angle of 15 degrees with respect to the coast normal. The groins are placed in such a way that they hold a constant ratio of distance over length $(\mathrm{Lg} / \mathrm{D})$. The simulations were run for 45 days.

Primarily, the model must be calibrated to keep an equilibrium no-groin condition. The main calibration factors are coefficients of the vanRijn sediment transport formulation. These coefficients are:

- SUS: coefficient for current-related suspended sediment transport (0.4)

- BED: coefficient for current related bed load sediment transport (0.2)

- SUSW: coefficient for wave related suspended sediment transport $(0.1)$

- BEDW: coefficient for wave related bed load sediment transport (0.3) The aforementioned calibration coefficients result in the cross-shore sediment contributions given in the Figure 3 below:

The Figure shows that the strongest crossshore sediment transport contribution is current related suspended sediment transport, but by calibrating the coefficients an even offshore and onshore sediment transport is achieved. The combination of the given coefficients contribute to the cross-shore profile given in the figure 5 below showing little changes in the cross-shore direction.

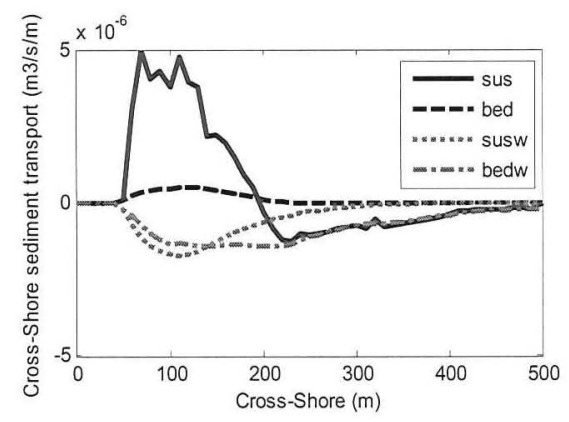

Figure 4 Cross-shore transport contributions (Positive offshore directed)

The sedimentation shown in the figure will be subtracted from the results in presence of the groins to achieve the net effect. Three different types of groins are considered in our case to trap sediment. One is extended outside the surf-zone $(\mathrm{Lg} / \mathrm{Lb}=1.2)$, one is extended until the breaker line, and one is entirely inside the surf-zone $(\mathrm{Lg} / \mathrm{Lb}=0.8)$; where $\mathrm{Lb}$ is width of the surf-zone. Three length over distance ratios are considered as well $(0.2,0.4 \& 0.8)$.

Based on the above calibration , a number of tests (see Table 1) for different groin combinations are carried

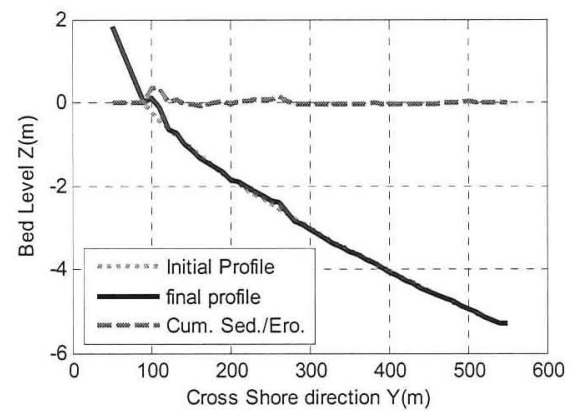

Figure 5, Initial and simulated crossshore profile and the corresponding net sedimentation and erosion 
out and some simulation results for one of the tests where the groins are not extended out of the surfzone (the most complicated physics are present) is presented below. Figure 6 shows the flow pattern around the groins, as a result of wave forcing (the only forcing on the system) and Figure 7 is the resulting bathymetry that can be compared with the initial bathymetry with completely parallel contour lines.

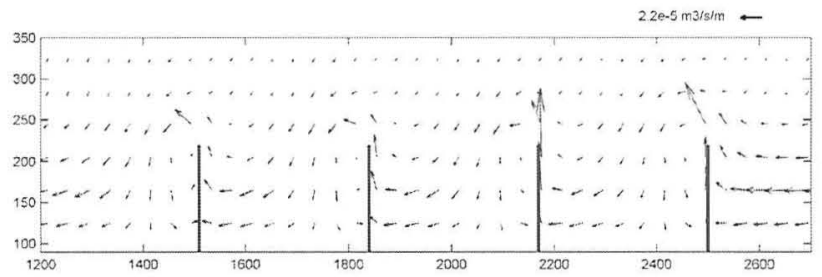

Figure 6. The alongshore flow pattern in presence of the groins (every 5 grid cell)

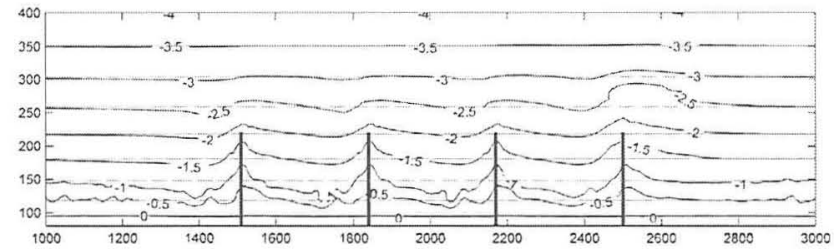

Figure 7, The net changes of the bathymetry in presence of groins after 45 days

(black solid contour lines), and the initial profile (red dashed lines)

The above figures show a qualitatively good agreement between simulations and expected profiles and patterns in the nature (e.g. see CIRIA 1990 or CEM 2003), but, there is still a high level of uncertainty in quantitative comparison due to limited data. Based on these simulations, the velocity vectors bringing sediment into the system are weaker than the vectors carrying sediment offshore. The sediment grains carried offshore accrete as soon as they reach hydro-dynamically smoother areas. This offshore-directed sediment loss from the system is compensated by wave asymmetry (wave related sediment transport contributions, SUSW \& BEDW, follow the wave propagation direction). To what extend this compensation occurs is highly dependent on local hydrodynamic characteristics in the nature, which must be seen in the calibration parameters (where the uncertainties arise). However, given all the uncertainties in sediment transport simulations, because of relatively acceptable hydrodynamic simulation, a general trend in the system can be seen, which makes it possible to compare different groin fields that share the same beach (different possible scenarios). Table 1 makes a quantitative comparison between different scenarios, and some of the quantities presented in the table are introduced below:

- Trap1 gives the total accretion in between the groins and upstream of the first groin, the area covers $X=1500-2700 \mathrm{~m}$

- Trap2 shows accretion only in between the groins; $X=1500-2500 \mathrm{~m}$

- Total Vol. is the cumulative volume that the groins encompass. Bounded to the $0 \mathrm{~m}$ contour line and is extended offshore of the groin-head. 
- Cum. Length no. of Groins X groin length, signifying construction costs

- Trap1/cum. Length symbolizing cost/benefit (trapping is treated as benefit)

Table 1 quantitative prediction of the groin fields performance (by Delft3D)

\begin{tabular}{c|c|c|c|c|c|c|c|c|c|c|c}
\hline ID & $\mathbf{L g} / \mathbf{L b}$ & $\mathbf{L g} / \mathbf{D}$ & $\mathrm{Lg}(\mathrm{m})$ & $\mathbf{D}(\mathbf{m})$ & $\begin{array}{c}\text { No. of } \\
\text { Groins }\end{array}$ & $\begin{array}{c}\text { Trap1 } \\
(\mathbf{m 3})\end{array}$ & Total Vol.(m3) & $\begin{array}{c}\text { Trap1/ } \\
\text { tot.vol. }\end{array}$ & cum. Iength & $\begin{array}{c}\text { trap1/ cum } \\
\text { length }\end{array}$ & $\begin{array}{c}\text { Trap2 } \\
\text { (m3) }\end{array}$ \\
\hline out1 & 1.2 & 0.2 & 200 & 1000 & 2 & 1383 & 419461 & $3.30 \mathrm{E}-03$ & 400 & 3.46 & -1950 \\
\hline out2 & 1.2 & 0.4 & 200 & 500 & 3 & 2307 & 419461 & $5.50 \mathrm{E}-03$ & 600 & 3.85 & -1065 \\
\hline out3 & 1.2 & 0.8 & 200 & 330 & 5 & 3220 & 419461 & $7.68 \mathrm{E}-03$ & 1000 & 3.22 & -194 \\
\hline break1 & 1 & 0.2 & 160 & 800 & 2 & 1491 & 281473 & $5.30 \mathrm{E}-03$ & 320 & 4.66 & 1001 \\
\hline break2 & 1 & 0.4 & 160 & 400 & 3 & 1913 & 281473 & $6.80 \mathrm{E}-03$ & 480 & 3.99 & 1393 \\
\hline break3 & 1 & 0.8 & 160 & 200 & 6 & 5169 & 281473 & $1.84 \mathrm{E}-02$ & 960 & 5.38 & 2040 \\
\hline in1 & 0.8 & 0.2 & 130 & 650 & 2 & 87.4 & 192520 & $4.54 \mathrm{E}-04$ & 260 & 0.34 & 114.5 \\
\hline in2 & 0.8 & 0.4 & 130 & 325 & 4 & 993.05 & 192520 & $5.16 \mathrm{E}-03$ & 520 & 1.91 & -1763 \\
\hline in3 & 0.8 & 0.8 & 130 & 163 & 7 & 2095 & 192520 & $1.09 \mathrm{E}-02$ & 910 & 2.30 & -732 \\
\hline
\end{tabular}

The above quantitative comparison shows that trapping always improves with increasing the number of groins $(\mathrm{Lg} / \mathrm{D})$ for all groin-lengths; and is a small fraction of the total volume to be protected (hardly $1 \%$ ). When the groin length and width of the surf-zone are similar accretion is maximized. The simple cost/benefit analysis shows that although increasing the number of groins improves performance of the system but it might be not always feasible (e.g. compare in 2 and in 3 ); of course, the value of the coast line might weight the analysis differently. The choice of $\mathrm{Lg}$ is relatively important, given that it might result in significant changes in the cost/benefit analysis (e.g. compare break3 and in3). Similar analysis can be done for different beaches and provides useful information in functional design phase.

\section{VALIDATION OF THE MODEL IN CASE OF T-HEAD GROINS}

Representation of complex structures in numerical models is a challenging task. T-Head groin is often recognized as an alternative for normal groin when the performance of normal groins is not convincing. Unfortunately, there are not many reliable datasets on application of T-Head groins. Hanson and Kraus 2001 studied the functionality of T-Head groins along Florida coast. Dabees \& Humiston 2004 did a numerical study on design of a system of T-Head groins for Gasparilla Island project, near the gulf coast of Florida, using simple morphological models, and recommended usage of these models for functional design optimization.

Ozolcer et al. 2006 deep sounding measurements of a coast in Trabzon province, Turkey, is used to verify the applicability of Delft3D. Further attention is paid on representation of the T-Head groins in the model. A beach with parallel contour lines and a slope of $1: 100$ is exposed to a wave field with $\mathrm{H}_{\mathrm{m} 0}=1 \mathrm{~m}$ and $\mathrm{T}_{\mathrm{m}}$ $1,0=5 \mathrm{sec}$. The waves approach the coast under an angle of 15 degrees relative to the coast normal. The bathymetry was the result of a survey six months after construction. A calibration was needed before the simulations to find the proper sediment transport coefficients to hold the least cross-shore sediment exchange (The result was $S U S=0.2$, SUSW $=0.2, B E D=0.2, B E D W=0.1$ ). Simulating the T-Head groins with the thin dams (See section for validation of normal groins) results in strong eddies in 
the shadow zones of the T-heads, due to zero friction in between the wall and the body of water. Various measures were considered to overcome the drawback:

1. Increasing bed roughness locally to compensate for lack of wall roughness

2. Placing the real body of the groin in the bathymetry (as an un-erosive bed change) (4X4m grid cells)

3. Applying a wall roughness

4. Placing the real body of the groins with higher resolution ( $2 \times 2 \mathrm{~m}$ grid cells)

The surveyed bathymetry is shown in Figure 8 below:

Post-processing of different alternatives above showed that locally increased bed roughness might improve the flow pattern, but as it explicitly results in an increase of bed shear stress, it creates large gradients in sediment transport, which might result in either not smooth bed changes or

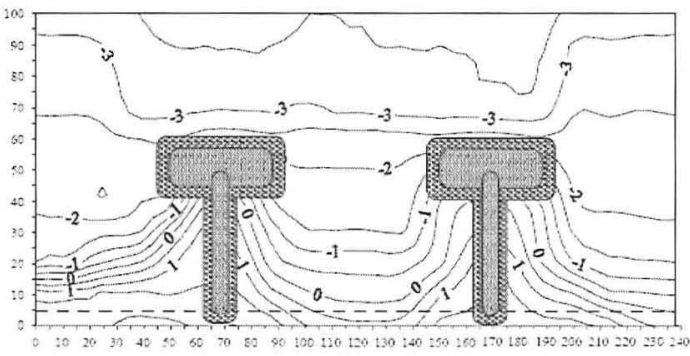

Figure 8, The surveyed bathymetry of the T- Head groin field by Ozolcer et al. 2004

numerical instabilities. Application of a wall roughness was potentially a good solution to damp strong eddies, but the current interpretation of the wall roughness needs a very large simulation area to avoid up-drift boundary effects. The most promising alternative is to simulate the real body of the groin in the bathymetry. It improved the flow pattern simulations qualitatively, due to a) reduction in the length of the $\mathrm{T}$ and the trunk part of the structure because of the thickness $b$ ) gradually varying flow field in between and outside the groin field. But, the smooth bed level changes was only comparable to the field survey (also quantitatively) when using higher resolution (20 computation grids along the groin). The resulting flow and sediment transport patterns are shown in the Figure 9 below:

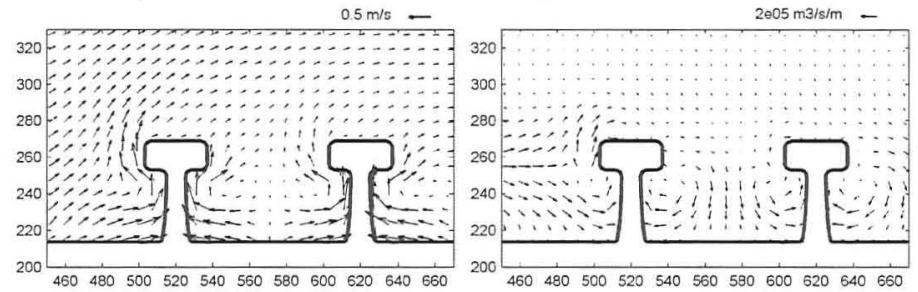

Figure 9, Sediment transport pattern following the Lagrangian velocity field vectors

(right), Eulerian velocity field vectors (Left). The vectors are every 5 grid cell

The above flow and sediment transport fields (for further illustration on Eulerian and Lagrangian velocities see Walstra et al. 2000 and Groeneweg 1999) resulted in the final computed bathymetry as Figure 10 below. 


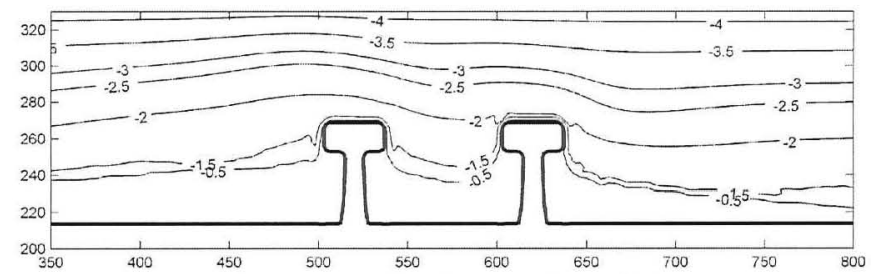

Figure 10, The simulated bathymetry by Delft3D, starting from a constant slope cross-shore profile after 6 months

The above figure resembles the expected bathymetry of Figure 8 in a reasonable manner both qualitatively and quantitatively, although showing difficulty of such simulations in general. The problem of a high resolution grid which means more computation time may be solved with local nesting of the grid.

\section{CONCLUSIONS AND RECOMMENDATIONS}

A process-based numerical model is verified against available datasets for application on simulation of straight open groins (against laboratory measurement), and T-Head groins (against field measurement). Based on the qualitative comparison made in case of normal (straight open) groins, an exercise is introduced on design of a groin field to trap sediment; showing a relatively proper approach to overcome the difficulties on functional design of the groin fields, although a lot of uncertainties are still present, both, in the model and in our understanding of the nature.

Delft3D was able to reproduce the major physical processes in presence of normal groins when verifying against Badiei et al. 1994 experiments. It also showed sensitivity of the model to different parameters such as various coefficients of VanRijn's sediment transport formulation, bed slope (important in cross-shore processes) and sediment size. Although, the laboratory case is hardly representing the nature (There is hardly any beach with a 1:10 slope having grain size of $0.2 \mathrm{~mm}$ in the nature), a general trend was observed in this study. In the next step, having a numerically generated cross-shore profile with a bar and trough, two combinations of groins with a constant ratio of length over distance $(\mathrm{Lg} / \mathrm{D})$ were simulated. The model results were qualitatively similar to the observed bed changes in case of long groins that are extended outside the surf zone $(\mathrm{Lg} / \mathrm{Lb}=1.4)$. In case of shorter groins $(\mathrm{Lg} / \mathrm{Lb}=0.8)$, when sediment bypassing was present, bed slope played an important role and different initial profile in simulation and laboratory explained the difference in simulation and measurement. Calibration of Delft3D for this case confirmed sensitivity of the model to sediment transport coefficients.

In the next phase, an exercise was introduced on design of groin fields. A Dean equilibrium profile was considered and different groin lengths and distances were tested and compared qualitatively with the expected flow patterns and bed changes. The flow patterns showed reasonably good agreement with what has been studied in different reports (e.g. CIRIA and CEM 2004). The exercise showed a possibility to assess performance of a groin field in functional design phase, using a process-based 3D model. Parameters, such as permeability of the groin, are not present in the flow model, while increased permeability is envisaged to improve trapping by reducing 
the offshore directed velocities (addressed by Kraus et al. 1994). The same exercise can be considered for a T-Head groin field.

Delft3D was also verified against a field case in Trabzon province of Turkey, on the Black Sea coast. The main purpose of this study was to find the best way to represent $\mathrm{T}$-Head groins in a model from both hydrodynamic and morphological point of view. The model tends to overestimate eddies in the shadow zone of the structure and to overcome the problem some measures were examined. Increased bed roughness along the trunk of the structure is an effective way to damp these eddies, but had direct influence on bed shear stress, therefore, high gradients and potential numerical instabilities did not provide an attractive approach for our purpose. Wall roughness was another effective tool, but its upstream boundary effects calls for larger simulation grid. It was shown that the precise body of the groins as an unerosive bed level change resulted in the best hydrodynamic pattern and morphological response compared to the measurements, especially when employing higher resolution (more than 20 grid cells along both dimensions of the structure).

\section{REFERENCES}

Badiei P., J. William Kamphuis, David G. Hamilton, 1994 "Physical Experiments on the Effects of Groins on Shore Morphology", Proc. ICCE 1994, pp 1782-1796

Briggs, M.J., Thompson, E.F., Vincent, C.L., 1995. Wave diffraction around breakwater. Journal of Waterway, Port, Coastal, and Ocean Engineering, ASCE 121 (1), 23-35.

Mohammad A. Dabees, Brett D. Moore \& Kenneth K. Humiston, "Enancement of T-Groin's design to improve downdrift Shoreline Response", Proc. ICCE 1994, pp 2423-2435

Fredsoe, J., 1984. "Turbulent boundary layer in wave-current interaction". ASCE Journal of Hydraulic Engineering 110, 1103-1120.

Goda, Y., 2000. Random Seas and Design of Maritime Structures. World Scientific, Singapore.

Hulsbergen C,H., Bakker W. T. Van Bochove G. (1976), "Experimental Verification of Groyne Theory", Proc. 15th Coastal Engineering Conf. pp 322-335

Ilic, S., Chadwick, A.J., Fleming, C., 2005. Detached breakwaters: an experimental investigation and implication for design -Part 1- hydrodynamics. Proceedings of ICE, Maritime Engineering.

Ilic, S., A.J. van der Westhuysen, J.A. Roelvink, A.J. Chadwick, 2007, Multidirectional wave transformation around detached breakwaters", Journal of Coastal Engineering 54, 775-789

Kraus N. C., Hans Hanson, Blomgren H. S., 1994, "Modern Functional Design of Groin Systems", Proc. ICCE 1994, pp. 1327-1342

Kraus N. C., Hans Hanson, 2001, "Chronic Beach Erosion Adjacent to Inlets and Remediation by Composite (T-Head) Groins", US Army Corps of Engineers

Mory, M., Hamm, L., 1997. Wave, set-up and currents around a detached breakwater submitted to regular and random wave forcing. Coastal Engineering 31, 77-96.

Ozolcer, I. H. , Komurcu, I. K.,Birben, A. R., Yusek, O., Karasu, S., 2006, "Effects of T-Shape Groin Parameters on Beach Accretion", Journal of Ocean Engineering 33 pp 382-403

SWAN user Manual, Technical Documentation (Holthuijsen et al.)

US Army Corps of Engineers, Coastal Engineering Manual (2003)

US Army Corps of Engineers, Shore Protection Manual (1984)

Leo C. van Rijn, 2009, "Prediction of Dune Erosion due to Storms", Journal of Coastal Engineering 56 pp $441-457$

Walstra, D.J.R., Roelvink, J.A., Groeneweg, J., 2000. "Calculation of wave- driven currents in a 3D mean flow model". Edge, B. Coastal Engineering vol. 2. ASCE, New York, pp. 1050- 1063.

Whitham, G.B., 1974: Linear and nonlinear waves, Wiley, New York, 636 p. 